\title{
Thermae et Ludus: \\ o início do turismo de saúde no \\ Brasil e no mundo
}

\author{
Thermae et Ludus: the beginning of the health tourism \\ in Brazil and in the world
}

Dario Luiz Dias Paixão

RESUMO: Por longo tempo, as termas, as estâncias e os balneários investiram em uma relação que marcou profundamente a sociedade: os banhos e 0 jogo. Estas duas atividades conviveram - e ainda convivem em muitos países - harmonicamente desde o auge do Império Romano à Belle Époque do turismo europeu. No Brasil, suntuosos hotéis-cassinos, aliados aos tratamentos com água, recebiam a nova burguesia voltada para a saúde e o entretenimento. Com a proibição do jogo no país, esses empreendimentos precisaram se reestruturar para sobreviver, alguns sem sucesso. Todavia, a volta do termalismo e dos cassinos na maior parte do mundo reabre discussões e polêmicas a respeito do papel do jogo no Brasil e suas relações com a atividade turística, carente de novos segmentos para competir com mercados já consolidados.

PALAVRAS-CHAVE: termalismo; cassinos; saúde; entretenimento; turismo.

ABSTRACT: For a long time, the spas, the ranches and the watering places invested in a relation that marked the society profoundly: the baths and the game. These two activities cohabited - and still cohabit in lots of countries -, harmoniously from the summit of the Roman Empire to Belle Époque of the European tourism. In Brazil, sumptuous hotels-casinos allied to the treatments with water, received the new bourgeoisie geared to the health and the entertainment. With the prohibition of the game in the country, these enterprises needed restructure to survive, some without success. However the return of thermalism and the casinos in the majority of the countries of the world reopens the discussions and polemics concerning the role of the game in Brazil

1. Bacharel em Turismo (UFPR); mestre em Turismo (Universidad de Las Palmas de Gran Canaria/ Espanha); doutor em Gestāo e Desenvolvimento do Turismo Sustentável (Universidade de Málaga/ Espanha); coordenador de Turismo (UNICENP - Centro Universitário Positivo). Contato: turismo@ unicenp.edu.br. 
and its relations with the tourist activity, deprived of new segments to compete with already consolidated markets.

KEYWORDS: thermalism; casinos; health; entertainment; tourism.

\section{Introdução}

Os "anos dourados" do turismo brasileiro surgiram a partir de 1920, com os cassinos incorporados aos hotéis de luxo e às estâncias termais, hidrominerais ou climáticas. Aproveitando os recursos naturais, de forma a produzir efeitos terapêuticos, surgiram edificações de porte, locais magníficos de realização de jogos e espetáculos, dignos de atender à alta classe e à elite acostumada à moda e à vida européia.

O Decreto n` 3.987, assinado pelo Presidente Epitácio Pessoa, em 2 de janeiro de 1920, visava a reorganizar os serviços de Saúde Pública. E, ao conceder autorização para a realização de jogos de azar, impulsionou os cassinos e as estações balneárias, termais e climáticas. Uma vez licenciados e sujeitos à taxa de cobrança de $15 \%$, estes complexos passaram a funcionar sem que incidissem nas disposições penais relativas ao jogo. O dinheiro arrecadado - previa o decreto - visava a formar um fundo especial para o custeio da profilaxia rural e das obras de saneamento básico no interior do Brasil. Esta "taxa de quinze por cento sobre o producto líquido dos jogos de azar licenciados" consubstanciou a forma de arrecadar (Decreto-lei nº 3.987, de 1920). Assim, o governo federal encontrou meios para fazer caixa e enfrentar as graves questões de saúde pública daquela difícil fase da vida brasileira.

No jogo e nas estâncias estava a solução para um mal endêmico e incurável: a própria saúde pública. Além da verba proveniente dos cassinos, o custeio se dava também pelo imposto auferido nas vendas de bebidas alcoólicas; as rendas dos laboratórios (exceção ao Instituto Oswaldo Cruz) e os saldos verificados nas diversas verbas do Departamento Nacional de Saúde Pública, subordinado ao Ministério da Justiça e Negócios Interiores.

Os reflexos da medida foram imediatos, como a construção do Copacabana Palace, o ponto de encontro mais comentado da alta sociedade da capital, onde seriam recebidas, ao longo de sua história, inúmeras celebridades. Albert Einstein, por exemplo, ali explicou, em 21 de março de 1925 - falando em alemão -, a Teoria da Relatividade (www.ronaldomourao.com). Eis o início da era dos cassinos no Brasil.

A sugestão partiu do então presidente da República, Epitácio Pessoa, acanhado com a falta de instalações adequadas para receber o rei Alberto I, da Bélgica, quando de sua visita oficial ao Brasil, em setembro de 1920. A concepção de um hotel de luxo à beira-mar sensibilizou o empresário Octávio Guinle. A exigência em anexar um cassino ao empreendimento foi aceita pelo presidente. Em seguida, o empreendedor escolheu uma área distante da população pobre da cidade, que possuía, na beira-mar, um dos seus passeios favoritos. Vencida a crítica da época, que desconfiava do êxito de um hotel-cassino construído "tão longe do centro do Rio de Janeiro", segundo os jornais da época, o Copa (apelido carinhoso) surgiu majestoso nas areias cariocas, visando às comemorações do Centenário de Independência. A inauguração só viria dia 13 de agosto de 1923, 11 meses depois do planejado, uma vez que não foram poucos os desafios enfrentados por Guinle. Uma violenta ressaca destruiu toda a avenida Atlântica meses antes da obra concluída, resultando em consideráveis estragos nos pavimentos inferiores do prédio.

A visão estratégica de Guinle mostrou-se correta. "O Copa viria a mudar o padrão de comportamento da classe dominante" (Boechat, 1999). Neste ponto, seu sonho assemelhou-se ao de Benjamim "Bugsy" Siegel, que se embrenhou em pleno deserto de Nevada, no afã de construir um luxuoso hotel-cassino, o Flamingo. Lá instalou as primeiras e populares máquinas caça-níqueis, inventadas, em 1895, pelo mecânico de carros Charles Fey. A inspiração de Bugsy, aparentemente abençoada, pois daria origem à cidade de Las Vegas de hoje, enfrentou problemas graves durante a construção e no início das atividades do empreendimento, o que comprometeu sua credibilidade. Ele acabou assassinado pela máfia, que havia abandonado os investimento nos cassinos de Cuba para apostar no sonho de Bugsy.

Paralelamente, a aviação comercial brasileira se tornou atividade importante para o desenvolvimento do turismo de saúde no início do século passado. O primeiro e importante passo foi a criação da S.A. Empresa de Viação Aérea Rio-grandense - VARIG, numa pequena sala da Associação Comercial de Porto Alegre, em 7 de maio de 1927. As viagens se intensificaram no Brasil e, nos dez anos seguintes, o número de companhias aéreas aumentou de quatro para nove.

A era Vargas deu marcas a uma nova estrutura social. Alterou a urbanização e enfatizou o debate político sobre a saúde pública. Mas o Brasil - à época com menos de 50 milhões de habitantes - estava ainda longe de tornar-se industrializado e competitivo no exterior. Em busca da saúde plena, a burguesia se voltou para a atividade turística com reflexos imediatos para o incremento das viagens e dos destinos. 
Histórico da relação: as antigas termas, as estâncias turísticas e os jogos de azar

\section{Os balneários e o jogo}

Cerca de 100 milhōes de pessoas formavam o Império Romano no século III da era cristã. Este palpitante superestado, defendido por 300 mil legionários bem pagos, era dirigido de Roma, uma efervescente circunferência de apenas 19 quilômetros. Quando o serviço de correio alcançou o recorde de 65 quilômetros por dia, mercadorias e pessoas dos mais diferentes rincōes faziam jus à máxima: todos os caminhos levam a Roma.

Naqueles dias, "a maioria das 1,8 mil casas suntuosas, contrastando com os 46,6 mil cortiços miseráveis” (Hauser, 1973) já dispunha de latrinas com água corrente. Este sistema de saneamento começara 200 anos antes, quando as águas do Fórum foram escoadas através da Cloaca Máxima, na verdade um grande coletor e principal dreno da Roma monárquica. Inspirado nas fontes etruscas, o saneamento era o diferencial da cidade e uma característica da vida romana. Os romanos criaram a figura da autoridade sanitária ao darem aos aediles - magistrados encarregados da fiscalização dos prédios públicos - a responsabilidade pela limpeza das ruas e pela distribuição das águas (hoje, a palavra "edil" é sinônimo de vereador). Mas o curioso é que não havia, nas leis romanas, qualquer menção de intervenção médica nos usos e costumes da época. Nem mesmo a Lex Regia (uma das mais antigas leis do mundo e que organizou a questão religiosa em Roma), atribuída a Numa, segundo rei de Roma, sublinhava a importância do médico em casos graves, porém autorizava, por exemplo, a abertura do corpo, na esperança de se retirar uma criança viva, no caso de uma mulher grávida que tivesse morrido. Essa é a origem da chamada "cesariana", método pelo qual o próprio César supostamente nasceu. Caio Júlio César redimiu-se desta ausência de valorização da classe médica, à época formada por escravos e/ou subalternos, pois, segundo o historiador latino Suetônio (c. 120 d.c.), "conferiu cidadania a todos os que praticavam a medicina em Roma (...) para torná-los mais desejosos de viver na cidade e induzir pessoas a recorrerem a ela" (Bailey, 1992).

Onze aquedutos traziam diariamente 1,3 bilhão de litros dé água fresca das montanhas para a capital. Balneários, cujos átrios abobadados eram milagres da engenharia, enchiam-se todos os dias de romanos a trocar boatos e se distrair (Gibbon, 2001).
O escritor militar romano Sexto Júlio Frontino (40-103 d.C.), em sua obra De aquis urbis Romae, explicou sobre os 14 aquedutos que seguiam o mesmo desenho (arcos semicirculares de pedra, montados sobre uma fileira de pilares) e abasteciam 856 banhos privados e as termas com 300 milhões de galōes de água potável. Frontino ainda registrou que "o imperador utilizava $17 \%$ da água de Roma, $39 \%$ era usada de maneira privada, e $44 \%$ era de uso público, subdivididos em $3 \%$ para os quartéis, 24\% para os edifícios públicos (incluídos 11 banhos públicos), $4 \%$ para os teatros, e $13 \%$ para as fontes" (www.cultura.pueblos-espana.org).

Além de serem lugares próprios para descanso, os banhos medicinais serviam para divertimento e higiene. Os de Agrippa - general amigo de Augusto -, hoje desaparecidos, constituíram o primeiro exemplo da concepção monumental das termas romanas dos séculos II e III, das quais as mais famosas foram as dos imperadores Diocletianus e Caracalla (o apelido advém do manto com capuz que o imperador Marco Aurélio Antonino Bassiano usava com freqüência).

Segundo De Masi (2003):

(...) no século I a.c. existiam, em Roma, 170 termas, e, no quarto século, já estavam na casa do milhar, e isto sem contar as 11 termas imperiais, enquanto Caracalla, por exemplo, recebia 9 mil pessoas/dia. Nas termas, não só existiam banheiros, piscinas, ginástica, farmácia, pontos de encontro, alamedas para passeio e terraços para se bronzear, como ambientes destinados aos jogos.

Já Gibbon (2001) comentou que as termas de Diocletianus foram erigidas entre 298 e 306 d.C., com 140 mil metros quadrados.

Continham mais de 3 mil assentos de mármore e o jorro permanente de água quente se derramava em espaçosas banheiras. O mais humilde dos romanos, por uma pequena moeda de cobre, tinha acesso ao diário desfrute de um cenário de pompa e luxo capaz de provocar a inveja dos reis da Ásia.

À medida que as termas públicas cresciam em importância, aumentavam as críticas contra elas, por estarem na contramão do cristianismo. De centros para uma vida saudável, passaram a ser combatidas como fator de degeneração dos costumes, e algumas se tornaram - de fato - enormes prostíbulos. Os banhos e os jogos mantinham raízes profundas nos usos e costumes das gens (famílias).

Clemente de Alexandria e São Cipriano pregaram contra a corrupção dos costumes nos banhos públicos mistos, e, no século seguinte, o IV d.C. no Concílio de Laodicéia (cidade da Ásia Menor que recebeu este nome em homenagem a Laodice, mulher de um dos reis da Síria) - assembléia eclesiástica -, cuja data mais admissível é 364 d.C., a Igreja recomendou que clérigos e fiéis não freqüentassem banhos abertos. 
No século V, por fatores como o contínuo esgotamento dos recursos hídricos, a destruição dos estabelecimentos pelos bárbaros (os visigodos tomaram Roma em 410 d.C., interrompendo os aquedutos e envenenando as águas), e, por fim, as crescentes restrições da moral cristã acabaram por determinar a ruína dos balneuns. Por séculos, acentuou-se o choque entre cristianismo versus paganismo, ou seja, "a moral cristã" contra os populares costumes tão fortemente arraigados. A idéia de vida saudável era agora combatida pelos pregadores, que proibiam radicalmente a presença da mulher nos jogos de azar que aconteciam nas termas.

Como forma de se protegerem destes ataques, pois não havia suficientes nascentes de água dentro das muralhas que rodeavam a cidade, os romanos construíram cisternas subterrâneas, com as águas fornecidas pelos rios e pelas nascentes das florestas. Uma das dignas de nota, e até hoje intacta, foi construída em 532, no Império Romano do Oriente, em Constantinopla (hoje, Istambul): a Cisterna de Yerebatan, próximo à Mesquita de Santa Sofia. Utilizada até ao século XV, e restaurada no século XIX, sua construção tem 336 colunas de diferentes estruturas romanas e sua capacidade total de água é de 80 mil metros cúbicos. Depois de um trabalho de restauração, a cisterna foi reaberta ao público em 1987. Turistas se encantavam com as luzes e a música clássica, que completavam a mística atmosfera da cisterna, onde foi filmado James Bond 007: from Russia with love. Atualmente, trata-se de um dos pontos turísticos mais freqüentados da Turquia.

O certo é que, no auge do Império, a Cidade Eterna era abastecida diariamente por mil litros de água per capita, sistema competente para suprir com folga a necessidade da população. Comparativamente, na Idade Média, mil anos depois, o retrocesso era tamanho que não havia nas cidades um litro sequer diário para cada habitante, gerando conseqüências graves para a saúde pública.

Na Idade Média, "ninguém praticamente tomou banho por mil anos" (Da Silva, 1998). Além da varíola, do cólera, da lepra e do tifo, a peste negra dizimava a população européia no século XIV. As áreas industriais cresciam rapidamente e os serviços de saneamento básico, como suprimento de água e limpeza de ruas, não acompanhavam essa expansão. Em conseqüência, o período foi marcado pela volta de graves doenças.

De forma sábia, as medidas de higiene pública e saneamento básico dos antigos visavam à prevenção e ao combate às epidemias. A figura do hospital - como hoje é concebida - foi, sobretudo, uma criação da cristandade da Alta Idade Média. Com o florescimento das cidades e o enriquecimento mercantil, os burgos desempenharam papel ativo na assistência, substituindo ou complementando, de algum modo, as obras de caridade da Igreja. Nesse período de fervor religioso, os leigos voltaram suas vidas à caridade, assistindo aos pobres e aos enfermos. Criaram-se inúmeras congregações e ordens seculares. Os concílios ordenaram a construção de hospitais na vizinhança dos mosteiros e das igrejas sob direção religiosa. Os primeiros hospitais eram dirigidos aos monges e, depois, surgiram os destinados aos estrangeiros, pobres e enfermos provenientes das grandes epidemias e guerras. "Apesar da total falta de condições higiênicas e de manutenção, a maioria dos hospitais medievais subsistia através de doações, oferendas e terras, e eram isentos de impostos" (Geovanini, 1995).

Os banhos públicos, em desuso, foram transferidos para o interior dos hospitais. As "misericórdias" eram estabelecimentos assistenciais que, pela escassez de seus meios e pela relação aos pobres - parte integrante e indispensável do reino de Deus -, assumiram a responsabilidade de zelar pela saúde pública. Nova resposta a um velho problema. Como uma das colunas-mestras do cristianismo é a caridade, os religiosos - freiras e monges - assumiram tais funções.

Na Alta Idade Média, cada mosteiro possuía, no mínimo, um infirmitorium (enfermaria) para tratamento dos monges e noviços que adoeciam; um irmãoenfermeiro, que era encarregado de prestar os cuidados básicos aos doentes, além de uma farmácia e, inclusive, um pequeno jardim botânico, com plantas medicinais.

Uma análise apurada da planta arquitetônica do mosteiro beneditino de Sankt Gallen, por exemplo, mostra duas cervejarias (uma interna) e duas padarias (uma externa para atender ao albergue dos peregrinos); a Igreja toma posição destacada no conjunto, enquanto, no piso superior, encontra-se a biblioteca e, no inferior, o scriptorium (lugar da escrita); os filhos dos nobres freqüentavam a escola em área contígua à hospedaria; a residência do médico localizava-se próximo ao horto das plantas medicinais e ao local das sangrias. Anexo ao hospital ficavam a cozinha e o local dos banhos para os doentes (os banhos, agora, eram internos, e não mais públicos). Para completar, uma capela dupla para o hospital e o noviciado (escola interna), além do cemitério e do pomar, davam um ar de graça ao complexo (www.ensp.unl.pt).

\section{As estâncias turísticas}

Segundo Da Silva \& Barreira (1994), termalismo designa de maneira genérica o "emprego de água mineral (crenoterapia), do clima (climatoterapia), do mar (talassoterapia), das areias e emanações radiativas (radioclimatoterapia) e do microclima de determinadas grutas, cavernas e galerias subterrâneas (espeleoterapia) com finalidades curativas."

Para Mourão: 
[...] o turismo de saúde se propõe a ser modalidade crenoterápica, na qualidade de inovação. Surgida recentemente, é destinada aos esgotados, estressados e acometidos de certas doenças crônicas de tratamento ambulatorial, que estão impedidos de permanecer por tempo mais prolongado nas estâncias, em virtude de seus afazeres profissionais, questōes econômicas e outras ocorrências particulares (Mourão apud: Da Silva \& Barreira, 1994).

De acordo com o Decreto no 20, de 13 de julho de 1972, diferenciaram-se as estâncias brasileiras em balneárias, climáticas e hidrominerais. O legislador caracterizou as balneárias como as possuidoras de praia, voltadas para o mar, com exceção das orlas marítimas compostas somente por rochas. Definiu, ainda, estâncias climáticas como sendo as que apresentavam um posto meteorológico instalado e em funcionamento ininterrupto durante, pelo menos, três anos, consideradas as temperaturas médias máximas e mínimas, umidade relativa média anual e número anual de horas de insolação. Para ser considerada estância hidromineral, o decreto determinou a necessidade de se ter fonte de água mineral, natural ou captada por meios artificiais e possuir, também, um balneário de uso público para tratamento crenoterápico, segundo a natureza das águas (Decreto-lei no 20, 1972, em Aulicino, 2001). Já as estâncias turísticas no Brasil, reguladas pelo Decreto $\mathrm{n}^{\mathrm{o}}$ 11.022, de 28 de dezembro de 1977, estabelecem a existência - como requisito mínimo - de atrativos de lazer e outros de natureza histórica, artística ou religiosa, ou de recursos naturais e paisagísticos (Decreto-lei no ${ }^{-11.022, ~ d e ~}$ 1977, em Aulicino, 2001).

Entende-se como estância, portanto, o lugar ou estação que recebe visitantes por algum tempo, seja pela busca de melhoria da saúde, seja por descanso ou conhecimento.

Spa-Francorchamps, localizada em Liége, na Bélgica, era o local preferido pelos “guerreiros" para a reposição de suas energias. Esta estação de águas originou o termo spa, que, em francês, tem o significado de fonte, ao passo que, em inglês, quer dizer estância mineral e está associado aos cuidados com a pessoa, em locais extremamente agradáveis. O fenômeno Gran Tour, dos séculos XVI e XVII, reacendeu a moda dos famosos balneários - centros termais e climáticos recomendados pelos médicos, graças à pureza do ar das montanhas e do mar - de Bath e Brighton, na Inglaterra; Aix-la-Chapelle e Schwalbach, na Alemanha; Biarritz, na França; e os Alpes, destacando-se Saint Moritz, na Suíça; e Chamonix, no Alto Savoia, famosa por abrigar competições olímpicas.

Após o sucesso dos balneários e das estâncias na Europa, muitos investidores seguiram os passos de seus antecessores, mas desta vez aliando a tranqüilidade destes lugares comparativamente aos frenéticos cassinos. Era preciso fazer com que a elite ociosa voltasse a se divertir. Segundo Paixão (1999), em vários países, somente em estâncias ou balneários as casas de jogos eram permitidas, como ordenou Napoleão Bonaparte, para atrair visitantes aos resorts, na época lugar de retiro para fins de lazer e saúde. "De fato, a fase de maior glamour do turismo aliou termalismo, cassinismo e paisagismo" (Rejowski, 2002).

No século XIX, novos destinos se tornaram muito famosos e, o jogo, de atividade complementar, passou à principal, além do que financiava o custo das megainstalações e do crescente número dos profissionais altamente qualificados que eram contratados. Alguns destes merecem destaque: Le Mont Charles (Monte Carlo), em Mônaco; Nice, Cannes e Vichy, na França; Blackpool, na Inglaterra; Marienbad, na Tchecoslováquia; Roullettebourg (O jogador, de Dostoiévski), Baden Baden, Wiesbaden e Karlsbaden, na Alemanha (baden significa banho); a Riviera Italiana; San Sebastian e Ilhas Canárias, na Espanha; e Cascais e Estoril, em Portugal (Paixão In: Trigo et al., 2005).

Além deles, destacam-se, na América do Norte, Atlantic City e Saratoga Springs, nos Estados Unidos, e Banff Springs Hotel, no Canadá. Na América do Sul já se sobressaíam Mar del Plata, na Argentina, e, no Chile, Viña del Mar e as de Chillán, cujas termas formam um complexo hoteleiro de montanhas com quatro opções de estadas, e onde estão concentradas as mais longas pistas de esqui da América do Sul. Muitos destes complexos inspiraram os profissionais ligados ao desenvolvimento das atividades de banho e de jogo e suas luxuosas construções por todo o Brasil.

\section{Os balneários e o jogo no Brasil}

Na América do Sul, onde o jogo foi sempre marcado por antecedentes históricos relacionados às festas populares, à loteria e às corridas de cavalos, os povos nativos já praticavam alguns jogos de azar antes da chegada dos colonizadores. No Rio de Janeirohavia uma conhecida casa de jogos, denominada "Beira-Mar Cassino, no antigo Passeio Público, que o Vice-Rei Luiz de Vasconcelos incumbiu a Mestre Valentim de construir à beira do cais, em 1789" (www.magocom.com.br).

Com a chegada dos europeus, despontaram novas hospedarias, restaurantes mais apresentáveis, rotas de trem e mudança nos usos e costumes, com ênfase à manutenção e à recuperação da saúde. Pobres e ricos temiam a proliferação de doenças ao se banharem em águas termais ou salgadas do mar. Para satisfação, nos locais de veraneio, encontravam as mesas de jogo. As primeiras regiões que receberam estes visitantes, na segunda metade do século XIX, foram as seguintes: Petrópolis, no Rio de Janeiro; Caxambu e Poços de Caldas, em Minas Gerais; Campos do Jordão, em São Paulo; e Santo Amaro e Caldas da Imperatriz, em Santa Catarina. No final do século XIX, o Brasil não estava nem perto de possuir hotéis e 
estâncias como as encontradas na Europa, muito menos de contratar profissionais com a experiência de Cézar Ritz, verdadeira lenda pelos seus consagrados métodos de gestão hoteleira e que inaugurou seu legendário hotel na capital francesa, no ano de 1898.

Mas, no início do século xx, o panorama começou a mudar. A chegada dos primeiros turistas internacionais se deu com a excursão da empresa Thomas Cook and Son, que, em 1907, trouxe o primeiro grupo organizado ao Rio de Janeiro, a bordo do navio a vapor Byron. O pai do turismo já havia falecido (1892) e cerca de 500 agências de viagem funcionavam pelo mundo quando o Brasil passou a receber turistas, no sentido pleno da palavra, e não apenas os comerciantes, imigrantes e viajantes de outras naturezas. Nesse mesmo ano de 1907, "a cidade passou a oferecer incentivos fiscais para construções de novos hotéis" (Gazeta Mercantil, 1999). E, segundo Rejowski (2002), “assim, consolidou-se a tendência do século anterior: no litoral, os banhos de mar, mas de forma mais elaborada e com disponibilidade de mais alguns serviços; no interior, as estâncias hidrominerais, termais e climáticas (a partir de 1910)".

Apesar de contratempos históricos, as décadas de 1920 e 1930 foram boas para a atividade turística nacional, quando os melhores exemplos do turismo de cura, e que estiveram muito na moda entre os viajantes, eram Campos do Jordão, em São Paulo, e Caldas Novas, em Goiás. Neste último destino, foram construídas casas de banho ainda nos anos 1920 (Barbosa, 2002).

Uma elitemilionária, fortalecida pelo Estado Novo, ocupava as mesas de jogo (destacava-se a imponente presença de Carmem Miranda nos shows do Cassino da Urca). Com produção milionária, as festas promovidas pelo Estado e pela elite eram, em geral, custeadas pelo empresário Joaquim Rolla, proprietário dos mais importantes cassinos do País, como os da Urca, de Icaraí, da Pampulha e de Araxá.

Este era o tempo dos cassinos, dos shows e das vedetes. O combustível estava racionado - inclusive para ambulâncias -, em função do início da II Guerra Mundial, em 1ํ de setembro de 1939. Mesmo com as despesas públicas rigorosamente contidas e o custo de vida subindo a todo vapor, em construção estava o luxuosíssimo Cassino de Quitandinha, entre vários outros pelo país.

\section{Os hotéis-cassinos brasileiros}

\section{Aspectos gerais}

O jogo organizado, que tanto prazer e dinheiro proporcionava às elites, precisava prosseguir e ampliar-se. E se o Rio de Janeiro já possuía os cassinos do
Copacabana Palace (considerado o primeiro do país), do Atlântico (no Posto 6, em Copacabana) e da Urca, Niterói tinha o Icaraí; Teresópolis, o Higino Palace; Santos, o Parque Balneário, o Ilha Porchat e o Atlântico; Guarujá, o Cassino do Barreiro; Poços de Caldas, o Quississana e o Politeama; Araxá, o Grande Hotel; Belo Horizonte, o Pampulha; Curitiba, o Ahú; Salvador, o Central; e Recife, o Grande Hotel. Petrópolis não poderia ficar para trás, pois lá personalidades importantes possuíam residências. As obras do Quitandinha demoraram três anos: em 12 de fevereiro de 1944, a casa foi parcialmente inaugurada.

No ato da proibição do jogo, existiam no Brasil 71 cassinos, que empregavam 60 mil trabalhadores direta e indiretamente. Estas casas de jogos ofereciam, além de ambiente de descontração - restaurante, salão de baile, bar e música -, a jogatina, sendo esta expressa por meio de jogos de cartas, roleta e bacará, dentre outras formas, sendo um ambiente no qual algumas pessoas acabavam por conhecer a riqueza ou a pobreza (Paixão, 1999).

Enquanto a elite discursava sobre a necessidade de investir neste tipo de ambiente seleto e voltado para a sociabilidade e a diversão sadia, as classes populares viam seus clubes de jogo serem acusados de locais perigosos à sociedade e à margem dos bons costumes. As famílias tradicionais exigiam luxo, segurança, higiene e boas atrações nos clubes, hotéis e cassinos, que garantiam o lazer após o trabalho. Diferente das classes trabalhadoras que, ao presenciarem seus patrões nas casas de jogos, eram levadas a imaginar que tais lugares os distanciavam do ganho financeiro justo e digno. O bom cidadão deveria prezar o trabalho e a família, estereótipo definido por Getúlio Vargas para o trabalhador que, realmente, amasse a nação e o trabalho.

Historicamente, a manutenção e a recuperação da saúde, associada ao divertimento e ao entretenimento por meio do jogo, sempre foi estratégia de hotéis-cassinos e resorts em diversos países, enquanto, no Brasil, durou apenas um quarto de século.

A regularização para uma estância hidromineral que abrigasse cassinos sempre coube aos governos nacionais ou locais. Os altos impostos eram aplicados a todos os estabelecimentos, fossem eles da iniciativa privada, do poder público ou, mesmo, mistos. Também firmavam com o governo contratos, em geral por dez anos (renováveis), para a exploração hidromineral. O complexo deveria abrigar hotel, restaurante, bar, piscina, salões, salas para conferências e festas beneficentes. As mulheres poderiam jogar nos cassinos, mas calcula-se que não representavam mais que $25 \%$ dos freqüentadores e deveriam estar sempre acompanhadas de seus maridos, mesmo nos shows e espetáculos (Ernst, 2003).

Ainda hoje é possível se ter uma idéia da sociabilidade existente entre homens e mulheres nos cassinos. As salas eram distintas para os jogos (roleta, bacará 


\section{E o debate continua}

Surpreendentemente, quatro meses depois de assumir a presidência, Eurico Gaspar Dutra convocou todo o Ministério e restabeleceu a vigência do artigo 50 da Lei de Contravenções Penais, fechando todos os cassinos do país. Até mesmo os que estavam amparados pela Lei das Estâncias de Águas foram proibidos de funcionar. O Cassino de Lambari, em Minas, funcionou apenas um dia. Outros não menos famosos, como o Quitandinha e o Grande Hotel Araxá, haviam investido grandes somas em suas implantações. Os 95 empregados do Cassino Ahú suscitaram na maior reclamatória trabalhista jamais tramitada na Justiça do Trabalho do Paraná, até então (Schwab, 1993).

Apesar de os jogos de azar serem interpretados e pensados, por vários séculos, como uma luz desfavorável à ética e à moral, normalmente alimentados por segmentos da Igreja, a maioria dos países ainda os utiliza como forma de arrecadação. Filósofos influenciaram as leis dos Estados com suas teorias, como, por exemplo, o francês Jean-Jacques Rousseau: "a base das leis é a vontade das pessoas expressadas por elas mesmas". Nos últimos dois séculos, as leis se aperfeiçoaram e o moderno consumidor parece não querer restrições, exceto quando elas são feitas para a sua própria proteção (Paixão \& Gândara, 1999).

Na medida em que é preciso planejar o futuro das políticas que atingem o jogo e a atividade turística no país, torna-se imperativo estudar as décadas de 1930 e 1940, fazendo emergir - sair de onde estavam mergulhados - estes importantes fatos que marcaram a história do Brasil e que, hoje, servem como balizamento para os estudiosos que pensam nas reais possibilidades de recuperação de balneários e estâncias.

Os locais das fontes de águas deram lugar a centros de diversão e lazer e deixaram na memória brasileira um amálgama de nostalgia, orgulho, saudade e esperança.

Enquanto prossegue o debate, a população brasileira continua na condição de grande apostadora, seja nas loterias oficiais, nas casas de jogos ilegais, nos cruzeiros marítimos que aqui aportam; seja, ainda, nos vários cassinos de fronteira, que contribuem para a fuga de divisas do país.

\section{Referências bibliográficas}

BARBOSA, Y. M. 2002. História das viagens e do turismo. São Paulo: Aleph. BAILEY, C. (Org.). 1992. O legado de Roma. Rio de Janeiro: Imago.

BOECHAT, Ricardo. 1999. Copacabana Palace: um hotel e sua história. São Paulo: DBA.
BRASIL. 1920. Decreto-lei n² 3.987, de 2 de janeiro de 1920. Rio de Janeiro: Congresso Nacional.

BRASIL. Decreto-lei nº 20, de 13 de julho de 1972. In: AULICINO, M. P. 2001.Turismo e estâncias: impactos e benefícios para os municípios. São Paulo: Futura.

BRASIL. Decreto-lei nº 9.215, de 30 de abril de 1946 (cópia original). In: SCHWAB, A. 1993. A música no Cassino Ahú. Curitiba: Secretaria de Estado da Cultura.

BRASIL. Decreto-lei nº 11.022, de 28 de dezembro de 1977. In: AULICINO, M.P. 2001. Turismo e estâncias: impactos e benefícios para os municípios. São Paulo: Futura.

DA SILVA, A. L. G. \& BARREIRA C. A. 1994. Turismo de saúde. São Paulo: SENAC.

DA SILVA, J. C. I. 2001. Grande Hotel São Pedro: o patrimônio cultural como fator de atração do turista. Dissertação de Mestrado em Turismo - Centro Universitário Ibero-americano, São Paulo.

DE MASI, D. 2003. Criatividade e grupos criativos. Rio de Janeiro: Sextante

ERNST, K.G. 2003. Memórias do Cassino Ahú: sociabilidade e relaçōes de gênero (Curitiba 1940-1946). Monografia de conclusão de curso. Curitiba: UTP.

GAZETA MERCANTIL. 1999. Análise setorial: a indústria hoteleira - vol. 1. São Paulo: Gazeta Mercantil. GEOVANINI, Telma et al. 1995. História da enfermagem: versōes e interpretaçōes. Rio de Janeiro: Revinter. GIBBON, E. 2001. Declinio e queda do Império Romano. São Paulo: Companhia das Letras.

HOUSER, E. 1973. O legado de Roma. Seleçōes do Reader's Digest, v. 3, n. 20. Lisboa: Ed. Reader's Digest. PAIXÃO, D. L. D. 2005.1930-1945, a belle-époque do turismo brasileiro: os hotéis-cassinos na era getulista. In: TRIGO et al. Análises regionais e globais do turismo brasileiro. São Paulo: Roca.

1999. La reimplantación de los casinos en Brasil y sus efectos en la actividad turística. Dissertação de Mestrado. Las Palmas de Gran Canaria: ULPGC.

PAIXĀO, D. L. D \& GÂNDARA, J. M. G. 1999. A legalização dos cassinos no Brasil: uma análise comparativa das situaçōes governamentais em outros países. Turismo - Visāo \&́ Açāo, v. 1, n. 2. Balncário Camboriú: Ed. da UNIVALI.

REJOWSKI, M. (Org.) 2002. Turismo no percurso do tempo. São Paulo: Aleph.

SILVA, E. R. 1998. O curso da água na história:simbologia, moralidade e a gestão de recursos hídricos. Tese (Doutorado) - UFRJ, Rio de Janeiro.

TRIGO, L. G. G. (Org.). 2005. Análises regionais e globais do turismo brasileiro. São Paulo: Roca.

\section{Sites consultados}

www.cultura.pueblos-espana.org. Acesso em: 13 mai. 2005

www.ensp.unl.pt. Acesso em: 14 mai. 2005.

www.magocom.com.br. (Boletim de Novidades Lotéricas) Artigo "Façam o jogo, senhores... Oswaldo Miranda ainda sonha com a reabertura dos cassinos". Acesso em: 18 out. 2004.

www.ronaldomurão.com.br. Acesso em: 10 mai. 2005.

Recebido em: 21/06/2006.

Aprovado em: 28/07/2006 